\title{
Pedagogía emocional en la formación profesional universitaria. Caso Alumnos de Ingeniería Ambiental. UNP. FCA. Filial Ayolas Misiones. Paraguay
}

\author{
Rosana Esmilce Rivaldi Guirland \\ rosanarivaldi@gmail.com \\ Facultad de Ciencias Aplicadas. \\ Carrera Ingeniería Ambiental. Filial Ayolas Misiones \\ Universidad Nacional de Pilar.
}

\section{RESUMEN}

La investigación describe la implicancia de la pedagogía emocional en la formación profesional universitaria de educandos de Ingeniería ambiental de la UNP. FCA. Filial Ayolas Misiones. 2018-2020. Responde al desafío de introducir en la formación universitaria la educación emocional desde una pedagogía integradora del sentir- pensar desde el equilibrio de las emociones, traducidos en desempeños en el perfil de egreso. Se sustenta en la investigación descriptiva con enfoque mixto, cualitativo - cuantitativo, estudio bibliográfico, documental y trabajo de campo. Se concluye que la pedagogía emocional está implicada en la formación profesional universitaria, en el desarrollo de contenidos actitudinales, consideración de la formación integral, ética, valores, transformación de pensamiento, asignaturas humanas y ambientales como función sustantiva de la docencia, en extensión e investigación, desde las gestiones ambientales que involucran las emociones. Se enfatiza una consideración indirecta y autónoma de aplicación que requiere ser atendida en forma sistemática y funcional.

Palabra clave: Pedagogía emocional - Educación universitaria - Desempeño integral 


\title{
Emotional pedagogy in university vocational training. Environmental Engineering Students Case. UNP. FCA. Filial Ayolas Misiones. \\ Paraguay
}

\begin{abstract}
The research describes the implication of emotional pedagogy in the university professional training of students of Environmental Engineering of the UNP. FCA. Ayolas Misiones subsidiary. 2018-2020. It responds to the challenge of introducing emotional education into university education from an integrating pedagogy of feelingthinking from the balance of emotions, translated into performances in the graduate profile. It is based on descriptive research with a mixed, qualitative - quantitative approach, bibliographic and documentary study and field work. It is concluded that emotional pedagogy is involved in university professional training, in the development of attitudinal content, consideration of comprehensive training, ethics, values, thought transformation, human and environmental subjects as a substantive function of teaching, extension and research, from environmental managements that involve emotions. An indirect and autonomous application consideration is emphasized that needs to be addressed in a systematic and functional way.
\end{abstract}

Key word: Emotional pedagogy - University education - Comprehensive performance

Artículo recibido: 15 marzo 2021 Aceptado para publicación: 19 abril 2021 Correspondencia: rosanarivaldi@gmail.com Conflictos de Interés: Ninguna que declarar 


\section{INTRODUCCIÓN}

"La Universidad no acorta las orejas", un dicho popular para criticar la actitud incoherente de un profesional con lo que se espera de él (según su título universitario). Ha llegado el momento de revertir esa expresión y encontrar la clave para que la formación universitaria sí logre acortar "las orejas de burro" que evidencian las limitaciones emocionales, en el relacionamiento del profesional/ egresado.

Esto nos lleva a preguntarnos si ¿En el mundo del trabajo actual es inminente el éxito laboral de un profesional con título universitario? ¿Las dificultades laborales tendrían más relación con los conocimientos, los procedimientos técnicos, las cuestiones emocionales, o la fusión de las tres dimensiones? ¿Cuáles son las metodologías, normas o reglamentaciones que han considerado la dimensión emocional desde la pedagogía? ¿Ese título profesional garantiza el manejo de las emociones propias y ajenas practicadas en la sala de clase? ¿En las salas de las universidades se debaten sobre las situaciones ilícitas en las que se han involucrado los mismos profesionales encargados de evitar o tratar tales situaciones y que condicionan el bienestar laboral? En este contexto surge el tema "Pedagogía emocional en la formación profesional universitaria."

La generación adulta actual observa alienada la realidad del momento, siente como superior a la generación actual, quizás por la era tecnológica que los deslumbra, sin embargo tienen tanto que enseñar, es menester no dejar en la literatura oral las grandes enseñanzas con el testimonio de vida de los padres que sin tener un título profesional tenían la sabiduría empírica o el aranduka'aty, que ilustraba la integralidad de su formación con el ilustre lema evidenciado con acciones "Moriré pobre pero honrado, a mi familia no le voy a hacer pasar vergüenza o no mancharé el apellido”, son estas las esencias a ser consideradas dentro de la matriz cultural del auténtico ser paraguayo.

La formación integral sale a relucir en situaciones de interacción social y toda la solvencia cognitiva y operativa se puede ver afectada por un desequilibrio emocional o afectivo, cobra importancia la integración de la Pedagogía emocional que consiste en un emergente campo disciplinar destinado al estudio de los factores afectivo- 
emocionales involucrados en los procesos educativos y al conocimiento de los fundamentos teórico educativos para el cultivo de las emociones, una formación en competencias emocionales en el contexto universitario (Núñez, 2008.)

El análisis surge en el contexto de situaciones de clases, en la lógica contextualización de las teorías de las diversas áreas del saber que han surgido de realidades concretas, las ciencias humanas, por la materia prima que estudia y las asignaturas técnicas por las noticias o avances que le caracterizan y que con facilidad salen a colación explicando una teoría, una fórmula o una situación problemática, estrategias de clases en la que se propicia la participación individual como actividad inicial, observación de diapositiva reflexiva aplicable a la realidad, el análisis o contextualización en situaciones laborales actuales de los contenidos programáticos, sustentos teóricos llevados a la realidad con ejemplos de situaciones vividas por los mismos alumnos, sus conocidos, familiares o vistos en los medios de comunicación, realidades que dan lugar a expresiones de preocupación del ejercicio profesional, que implica la intervención de la actitud personal en la interrelación humana y toda esa confluencia englobada en la dimensión emocional, sirve de sustento e impulso a la gran pregunta:

¿Es considerada la Pedagogía emocional en la formación integral, propuesta por el desarrollo curricular, de acuerdo al perfil profesional de egreso del educando universitario?

\section{Enfatizadas en las interrogaciones:}

¿Cuáles son los factores que condicionan la relación pedagógica del Educador con el Educando?

¿Cuáles son las situaciones de aprendizaje que guardan relación con la educación emocional?

¿Cuáles son los sustentos científicos que respaldan la incorporación de la Pedagogía emocional en la formación profesional universitaria?

El enfoque actual de la educación por competencias, desde el enfoque cognitivo y el desarrollo humano que llega al ámbito universitario, implica desarrollar las capacidades básicas del hombre que guardan relación directa con las inteligencias múltiples, son los aportes científicos o epistemológicos fundamentales que sustentan las metodologías que han de considerar como ideas claves las actitudes, la inteligencia emocional, o social, intrapersonal e interpersonal. Se considera la situación actual que condiciona la 
necesidad, la relación docente, alumno y como condiciona la necesidad de una pedagogía emocional que configure el gobierno de las emociones.

\section{La política de la Educación Superior en Paraguay.}

Al desentrañar la concreción de una política, se encuentra en las actividades que se transforman en resultados, es cuando se comprueba la necesidad de ir actualizando de acuerdo a las exigencias emergentes, que lógicamente pasa por la percepción del ser humano, y es precisamente el bienestar integral de la persona individual y social en quien se evidencia. De ahí la importancia de la Política de la Educación Superior para ir encontrando aspectos que corroboren la necesidad de una pedagogía emocional en la formación profesional universitaria.

Toda persona tiene derecho a la educación integral y permanente, que como sistema y proceso se realiza en el contexto de la cultura de la comunidad. Sus fines son el desarrollo pleno de la personalidad humana y la promoción de la libertad y la paz, la justicia social, la solidaridad, la cooperación y la integración de los pueblos; el respeto a los derechos humanos y los principios democráticos; la afirmación del compromiso con la Patria, de la identidad cultural y la formación intelectual, moral y cívica, así como la eliminación de los contenidos educativos de carácter discriminatorio. La erradicación del analfabetismo y la capacitación para el trabajo son objetivos permanentes del sistema educativo. (Const., 1992, art.73)

Se enfatiza el derecho a la educación integral, desarrollo pleno de la personalidad humana, el respeto a los derechos humanos y los principios democráticos, para relacionar con el desarrollo humano integral que ocupa al sistema educativo.

Contextualizar la Constitución Nacional en la Ley de Educación Superior 4995/13 se puede ilustrar el respaldo de las ciencias humanas en la formación al igual que la científica y la tecnológica.

Uno de los objetivos de la Educación Superior reza literalmente: Ofrecer una formación científica, humanística y tecnológica del más alto nivel académico. (Ley 4995, 2013, Art. 6, inc. b.)

En un documento del C O N E C, Estrategias de Transformación de la Educación Superior, dado a conocer en el año 2002, se sostiene que "El mejoramiento de la calidad de la educación constituye el principal desafío de la universidad paraguaya", lo cual 
supone - de acuerdo al referido documento - "no solamente la tarea de superar el rezago organizativo institucional, claramente visible cualquiera sea el parámetro de comparación que se adopte, sino, además, la de incorporar nuevas dimensiones del conocimiento humano que ya forman parte del acervo de la cultura contemporánea". (Rivarola, 2003, pág. 73)

Como se evidencia hay expresiones que son cualitativas en esencia, en auge en la actualidad como mejoramiento de la calidad, que afecta a toda la política de la educación superior, a toda la organización, la administración, lo pedagógico y lo comunitario. Se valora además el desafío de incorporar nuevas dimensiones del conocimiento humano, he aquí un gran impulso para reconocer a la educación emocional, como esa nueva dimensión que va cobrando espacio en el presente siglo, para recuperarle el sentido a la humanidad que sufre del vacío existencial.

La educación superior es la que se desarrolla en el tercer nivel del sistema educativo nacional, con posterioridad a la educación media. Tiene por objeto la formación personal, académica y profesional de los estudiantes, así como la producción de conocimientos, el desarrollo del saber y del pensamiento en las diversas disciplinas y la extensión de la cultura y los servicios a la sociedad. La educación superior es un bien público y, por ende, es un factor fundamental para el desarrollo del país, en democracia y con equidad. Ley 4995/2013 “De Educación Superior”, art. $2^{\circ}$

En la misma Constitución Nacional se da por asentado en el objeto expresiones como la formación personal, bien público, en democracia y con equidad, es decir aquello que se debe observar en el comportamiento de los egresados universitarios, no solo en lo académico y profesional sino inicialmente en su formación como persona individual con su historial a ser atendido, influido y mejorado y de todos los habitantes al ser un bien público, lo correcto, el ideal, sumada a la democracia, palabra tan mencionada pero no comprendida al juzgar por los resultados, lo bueno para cada uno y por ende para todos en una coincidencia en el bienestar básico, y ahí surge la necesidad de la equidad, a cada uno lo necesario según su requerimiento. Se explica la implicancia emocional que supone tener la actitud personal, democrática, de quien es atendido con equidad y actúa de igual forma al compartir el bien público que ha recibido como una pieza del pueblo.

\section{Responsabilidad Social y Misión de la Educación Superior en el Libro Blanco}


La Responsabilidad Social (RS) es un enfoque de gerencia ética e inteligente, que en el caso de las Instituciones de Educación Superior contempla tanto los impactos que genera ésta en su entorno humano, social y natural, como su papel activo en la promoción del Desarrollo Humano Sostenible (DHS). Se la concibe como una estrategia racional de desarrollo para la inteligencia organizacional, que pide a las IES responder por sus acciones y consecuencias en su entorno y a los diversos grupos interesados o afectados por dichas acciones y consecuencias.

La ética de la responsabilidad por los efectos (cercanos como lejanos) que nuestra presencia en el mundo genera, nos exige preocuparnos por el mundo presente y futuro, ser actores partícipes de la solución de los más agudos problemas de nuestra sociedad. El interés corporativo bien entendido no puede dejar de ser sensible a la sociedad en la cual se desarrolla la organización, y tiene que reconocer las "intersolidaridades", como dice Morin (1999).

Buscando que el futuro egresado alcance un perfil profesional con responsabilidad social, las IES pueden implementar procesos de: a) organización interna, b) formación académica, c) investigación aplicada y d) participación social que promueven dinámicas de aprendizaje e integración de los valores de solidaridad, responsabilidad, democracia, justicia social y desarrollo sostenible, para toda la comunidad universitaria (personal administrativo y de servicio [PAS], docentes y estudiantes) y colaboradores externos (Valleys, 2011).

Las IES, también tienen un impacto sobre la sociedad y en el desarrollo económico, social y político; en cuanto forma a sus profesionales y líderes; es un referente y un actor social que puede promover el progreso, crear capital social, vincular la educación de los estudiantes con la realidad social exterior, hacer accesible el conocimiento a todos y constituirse en un interlocutor válido en la solución de sus problemas y de servicio de universidades e institutos superiores, centros de investigación, empresas y cooperativas, agencias de cooperación; gobernaciones y municipalidades; representantes de la sociedad civil y del Estado, se delinearon seis ejes temáticos, a la razón:

- Organización, gobierno y financiamiento de la Educación Superior

- Cooperación e internacionalización

- Formación del docente de la Educación Superior

- Investigación, desarrollo e innovación para el desarrollo del país 
- Instituciones de Educación Superior y entorno social

- Aseguramiento de la calidad de la Educación Superior

Es tarea de las IES la formación integral que permita a los profesionales intervenir en el entorno con las competencias necesarias para generar dinámicas de cambio, hacia una sociedad más justa y solidaria, teniendo en cuenta el contexto sociocultural.

Se debe incorporar dentro del perfil del egresado, la formación de profesionales altamente capacitados, sensibles a los problemas del entorno y que se comprometan con el desarrollo de la región, considerando que la universidad debe ser una entidad que convoca para el análisis y la búsqueda de soluciones alternativas a los problemas sociales.

\section{Contextualización en la UNP - Facultad de Ciencias Aplicadas. MISIÓN FCA-UNP}

- Formar profesionales competentes, éticos, creativos, críticos; generando conocimiento científico - tecnológico como respuesta a los requerimientos actuales, en interacción con el contexto socioeconómico, cultural y ambiental.

\section{VALORES FCA-UNP}

En la búsqueda de los siguientes valores, los miembros de la comunidad educativa de la FCA se orientarán por las definiciones que se plantean a continuación:

\section{a. RESPETO}

- Actuar y conducirse de acuerdo con las normativas institucionales vigentes.

- Actuar y conducirse con dignidad hacia la sociedad en general, con independencia de género, raza, capacidades especiales, edad, credo, filiación, preferencia sexual, convicción política o nivel jerárquico.

- Hacer uso correcto de los bienes institucionales, garantizando con ello la preservación del patrimonio universitario.

- Respetar en todo momento la propiedad intelectual que genere cualquier miembro de la comunidad universitaria y de la sociedad en general, reconociendo siempre a sus creadores, autores e inventores

- Respetar la libertad de opiniones y convicciones, en un clima de armonía, pluralidad y participación responsable.

\section{b. CREATIVIDAD}

- Promover la libre manifestación de las ideas. 
- Encontrar soluciones a los problemas del entorno.

- Incentivar una actitud proactiva y de superación permanente

c. RESPONSABILIDAD

- Responsabilidad, se utiliza también para referirse a la obligación de responder ante un

- Hecho prefijo re-, que alude a la idea de repetición, de volverá atrás, y el verbo spondere, que significa "prometer", "obligarse" o "comprometerse".

\section{d. LIBERTAD}

- Libertad es la facultad o capacidad del ser humano de actuar o no actuar siguiendo según su criterio y voluntad. Libertad es también el estado o la condición en que se encuentra una persona. 3

\section{e. DEMOCRACIA}

- Organizarse en un conjunto de individuos, en el cual el poder no radica en una sola persona, sino que se distribuye entre todos los estamentos componentes de la Institución.

- Tomar decisiones según la opinión de la mayoría.

- Determinar la conducta basada en las reglas, para una convivencia ordenada, política y socialmente.

- Respetar la dignidad humana, a la libertad y a los derechos de todos y cada uno de los

\section{f. HONESTIDAD}

- Actuar con la verdad, hacer siempre lo correcto.

- Comportarse y expresarse con coherencia de acuerdo a los valores institucionales.

\section{g. SERVICIO/SOLIDARIDAD}

- Brindar a todas las personas un trato justo, cordial y equitativo; orientado hacia el compromiso social.

- Promover y actuar en pro del medio ambiente, la salud pública y el entorno.

- Procede del latín responsum, del verbo respondere, que a su vez se forma con él.

\section{Propuesta pedagógica y enfoque curricular.}

La propuesta pedagógica de la Facultad de Ciencias Aplicadas se sustenta en el Modelo Educativo Centrado en el Aprendizaje, el mismo se basa en el aprendizaje dentro de una situación real, es decir, que no se puede estudiar de forma abstracta, sino que éste debe 
ser interpretado en el contexto en el que se produce, señalando que la educación es un proceso interactivo y dinámico.

El enfoque curricular adoptado por la UNP en el año 2010 denominado Cognitivo y de Realización Personal se refiere a una ejecución integradora de aspectos variados del conocimiento, lo cual incluye potenciar aptitudes, rasgos de personalidad, conocimientos teóricos y praxis social. El mismo está desglosado en competencias genéricas y específicas las cuales están establecidas en el plan de estudios de las carreras, y se desarrollan en el planeamiento de las cátedras, con seguimiento en el Libro de Cátedras y en documentos establecidos para el efecto, a fin de dar cumplimiento al perfil de egreso.

\section{Programa de Especialización en Didáctica Universitaria.}

Actualmente las exigencias de la sociedad y, particularmente, la de la región donde está inserta la UNP, demandan al catedrático universitario un desempeño profesional de la docencia, el cual, significa que ya no basta el "saber hacer" es decir, ser hábil en el manejo de los procedimientos científico-técnicos para dirigir el aprendizaje. Se necesita docentes universitarios críticos que propicien cambios paradigmáticos.

Ante esta situación académica, la Escuela de Postgrado propone un Proyecto Educativo que pretende fortalecer la formación profesional pero con una perspectiva de innovación general y contextualizada del docente universitario.

\section{Este Proyecto se sustenta en los siguientes principios generales:}

Visión amplia y crítica sobre los procesos innovadores del contexto social, político, cultural, epistemológico, pedagógico, filosófico y disciplinares que componen la complejidad de las prácticas educativas transformadoras del sujeto de la educación y de su realidad situada.

Implementación de la metodología científica articulada con otras estrategias didácticas, durante el desarrollo de los contenidos programáticos tendientes al logro de las capacidades.

La UNP apunta, a la continua formación del docente universitario que no sólo domine el contenido, sino que sepa interpretar de manera plural su realidad, la de sus alumnos y el entorno social en el que se circunscribe, para educar buscando la transformación de su pensamiento y la de sus alumnos, incentivando la reflexión crítica, la actitud positiva y el compromiso con la gestión innovadora de la institución. 
La contextualización social emergente. Seres humanos descomunicados en la era de la información.

Las interdependencias se han multiplicado. La conciencia de ser solidarios con su vida y con su muerte liga desde ahora a los humanos. La comunicación triunfa; el planeta está atravesado por redes, faxes, teléfonos celulares, módems, internet. Y, sin embargo, la incomprensión sigue siendo general. Sin duda hay grandes y múltiples progresos de la comprensión, pero los progresos de la incomprensión parecen aún más grandes...Educar para comprender la matemática o cualquier disciplina es una cosa; educar para la comprensión humana es otra; ahí se encuentra justamente la misión espiritual de la educación: enseñar la comprensión entre las personas como condición y garantía de la solidaridad intelectual y moral de la humanidad.

El problema de la comprensión está doblemente polarizado:-Un polo, ahora planetario, es el de la comprensión entre humanos - Un polo individual es el de las relaciones particulares entre familiares. Morín (2006, p. 91)

La comprensión es a la vez medio y fin de la comunicación humana. Los habitantes del planeta necesitan comprensiones mutuas en todos los sentidos. Dada la importancia de la educación en la comprensión necesita una reforma planetaria de las mentalidades; ésa debe ser la labor de la educación del futuro.

Seres humanos des-comunicados en la era de la información, la ausencia de la sintonía de las aspiraciones comunes de los seres humanos se ve afectada por el egocentrismo, que separa hermanos, familias, al supervalorar el tener por sobre el ser, a nivel micro y macro, las potencias mundiales crecen vendiendo petróleo y contaminando el recurso hídrico que se preludia una escasez que azotará la humanidad y uno piensa, mejor caminando o en los medios más antiguos como los burros y caballos antes que dejar de existir por idolatrar los vehículos que funcionan con la base petrolífera. Es tan lógica al parecer la necesidad de alianza de acuerdos y prácticas por situaciones de vida o muerte, que la ceguera de los magnates son los dominantes del mundo entero.

\section{"La inteligencia múltiple" como respuesta a la crisis educativa.}

En las Escuelas tradicionales solo triunfa el que sabe leer, escribir y calcular, inteligencias lingüísticas y de matemáticas, sin embargo se han demostrado la presencia de otras inteligencias que de hecho en la realidad condicionan el éxito del ser humano, pero que al no ser estimulados como corresponden también pudieron no ser 
desarrollados condenando al fracaso a los que no han tenido la predisposición lingüística y matemática.

Según Howard Gardner, el ser humano poseería ocho puntos diferentes de su cerebro donde se albergarían diferentes inteligencias. Aunque ese científico afirme que el número ocho es relativamente subjetivo, son esas las inteligencias que caracterizan lo que él denomina inteligencias múltiples. Estas son: la inteligencia lingüística o verbal, la lógico-matemática, la espacial, la musical, la cenestésica corporal, la naturalista y las inteligencias personales, esto es, la intrapersonal y la interpersonal.

Como sucede con las demás inteligencias, excepto la pictórica, es también posible identificar un modelos evolutivo de desarrollo y el centro neuronal de las emociones de donde parecen salir las descarga de ira, de miedo, de increíble sensación de amor, de sorpresa, de repugnancia, de tristeza y sobre todo de felicidad que nos deslumbra por momentos, aunque no existan razones aparentes para esa manifestación.

Las inteligencias personales, la interpersonal es la capacidad de percibir y comprender a otras personas, descubrir las fuerzas que las impulsan y sentir gran empatía por el prójimo indistinto. La intrapersonal, capacidad de autoestima, automotivación, de formación de un modelo coherente y verdadero de sí mismo y del uso de ese modelo para llevar a cabo la creación de la felicidad personal y social. Las habilidades desarrolladas son las de interactuar, percibir, relacionarse con empatía, mostrar autoestima y autoconocimiento y ser ético. Antunes (2006, p. 100)

La naturaleza humana busca el bienestar, pero ese estar bien, sentirse bien, está comprobado que lo experimenta por medio de su sistema nervioso, no es casual, tampoco es espontáneo, tiene un proceso semejante a la vieja inteligencia, que puede ser desarrollada en la Escuela. Desde el momento en que se trata de seres humanos, es necesario lograr el sentirse bien, se busca evitar el disgusto, la tristeza dentro de lo posible. Por lo tanto esta inteligencia social, que busca primero el bienestar dentro de la misma persona, la intra personal y con los demás la interpersonal es la clave para lograr ese bienestar tan anhelado pero que hasta hoy se le atribuye al azar, a la suerte, al carácter, a la forma de ser heredada, a los demás, al tiempo a cualquier cosa pero hasta se resignan a la infelicidad y al mar humor como algo inherente a la condición individual. Sin embargo este hallazgo científico, que si bien no son componentes materiales nuevos en otros planetas que respalden que hay otras formas de vidas, sí es 
un gran descubrimiento que aprovechado como corresponde podrá hacer plena la vida de los seres humanos aquí en la tierra y su repercusión colectiva podría tener efectos trascendentales en la humanidad.

"La buena noticia es que la inteligencia emocional se puede aprender. Las innovadoras estrategias que plantea ayudarán a erradicar la violencia y otros rasgos negativos que son la causa de muchos males que aquejan a nuestras familias y a nuestra sociedad. ¿Por qué algunas personas parecen dotadas de un don especial que les permite vivir bien aunque no sean las que más se destacan por su inteligencia? ¿Por qué no siempre el alumno más inteligente termina siendo el adulto que más éxito tiene en el trabajo? ¿Por qué algunos son más capaces que otros de enfrentar contratiempos, superar obstáculos y ver las dificultades bajo una óptica distinta? .Un nuevo concepto viene a darnos respuesta a estas interrogantes. Es la inteligencia emocional la que nos permite tomar conciencia de nuestras emociones, comprender los sentimientos de los demás, tolerar las presiones y frustraciones que soportamos en el trabajo, incrementar nuestra capacidad de empatía y nuestras habilidades sociales, y aumentar nuestras posibilidades de desarrollo social. Goleman (2000)

Aquí está la esencia científica "la inteligencia emocional", esa competencia para poder elegir entre las opciones para movernos en consecuencia sabiendo que nos traerá una alegría, un disgusto o una curiosidad, pero que lo hemos decidido sabiendo y por lo tanto predispuestos a aprovechar la situación individual o social para encaminar o buscar el bienestar personal y profesional tan anhelado.

Aquí cobra protagonismo, la institución educativa con la buena noticia de que la inteligencia emocional puede ser aprendida, y con ella toda una revolución del comportamiento humano, y considerando que los adultos son los seres conscientes, se introduce la consideración en el ámbito universitario, ahí en donde se forman los profesionales, para poder entender como intervienen las emociones en esa pedagogía desarrollada en la interacción del docente con el alumno.

\section{Actualización de la relación afectiva docente-alumno.}

Los actores educativos fundamentales el educador y el educando, no tienen una relación informal, casual, la interacción tiene una intención de encaminar, dirigir encausar hacia un aprendizaje, todo es intencional, todo tiene un porque y un para qué y aquí nos detenemos a abalizar el cómo, la metodología, la técnica, las palabras, las actitudes en 
función a ese ser en formación de hacia ese ser profesionalmente formado, de ahí la nobleza y la delicadeza de la misión educativa, el trabajo con seres humanos de un tiempo y de un espacio determinado, inserto en una realidad socio cultural con una individualidad biopsicosocial. En ese sentido (Chabot, 2009, p. 17) expresa “A partir de ahora, cuando se hable de estrategias pedagógicas, será necesario comprender la importancia de las competencias emocionales y de las emociones en los procesos de aprendizajes.

Las emociones, la capacidad para manejar las emociones en el proceso del desarrollo de las estrategias, en los procesos de debates, en las confrontaciones de opiniones entre compañeros, en los temas que afecten a compañeros o a la misma profesora que hasta podrían ser de conocimiento del grupo por suceder en la misma institución o comunidad, demanda del desarrollo de un conjunto de capacidades, conocimientos, habilidades y destrezas para articular las emociones propias y de los educando y de ellos entre sí, para lograr el aprendizaje deseado incluso más productivo al manejarlo con la solvencia necesaria.

Desde la relación educativa las exigencias al educador toman la forma de condiciones que favorecen el contacto entre educador y educando.

La estabilidad emocional y el dominio de sí mismo como fuentes de la autoridad, la serenidad y el optimismo, la paciencia y la perseverancia, la comprensión y la clarividencia, el interés por los alumnos y su trabajo son imprescindibles para establecer la relación educativa". Esta concepción sirve como antecedente significativo de cómo se enseña con la forma de ser del profesional de la educación, una realidad tan lógica pero no comprendida por tantas personas que no quieren ser tratados como ellos mismos están tratando como si tuvieran el derecho por la edad o por el título y más aún en el nivel universitario se observan personalidades frías y rígidas que están automatizados como reproductores de teorías y no admiten ningún cuestionamiento, a la luz de lo expuesto como si no tuviesen una inteligencia emocional que los vuelva humanos. (Leroy 1970, c.p.Fermoso 1990, p.256)

Y para ilustrar aún más el amor necesario en la interacción pedagógica le citamos a (Fermoso 1990) que interpreta expresiones de otros autores clásicos con el afán de subrayar los indicios de lo afectivo - emocional en la educación desde antaño: Una forma bastante común a teóricos que encumbraron la personalidad del maestro y su 
proyección afectiva sobre los alumnos es la defensa del eros pedagógico, con una historia tan larga como es el tiempo transcurrido entre Platón y el existencialismo. El idealista Platón hizo intervenir esta fuerza de simpatía en el proceso de comunicación del hombre con el mundo de las Ideas; Spranger lo entiende como "amor de donación hacia el alma del otro", que desarrolla la sensibilidad axiológica y el poder creador de valores en el educando; Max Scheler analiza el acto de amor, que es una entrega al otro y una dirección del valor inferior hacia el superior. Sin embargo el eros pedagógico no ha de confundirse con el sentimiento erótico, ni han sido la intención de cuantos han usado la fórmula platónica.

\section{La comunicación educativa y el formador del tercer milenio.}

Y justamente para responder a la paradoja, estamos en un siglo con avanzados medios de comunicación y seres humanos cada vez más incomunicados, deshumanizados, seguimos con el deslumbramiento con lo nuevo, como con el espejo que nuestros ancestros indígenas. Estamos convirtiéndonos en idiotas por la tecnología como ya lo anunciara Albert Einstein "La tecnología nos convertirá a los seres humanos en una sociedad de idiotas". Es tan fácil aparentemente diferenciar el valor de la persona en cuerpo presente a mi lado comparando con la otra persona al otro lado de la línea del celular que me envía un mensaje, sin embargo la realidad es verle en nuestro entorno a nuestros adolescentes y jóvenes y hasta adultos estar inmersos en el celular, respondiendo con gestos o balbuceos a quienes dirijan una pregunta sin desprender la mirada y los dedos del celular, de la computadora, del televisión o del video juegos para el caso de los niños. Todos vemos como una realidad que invade y no estamos haciendo nada, hacia donde le conduce esto a la humanidad. Ya no se detiene la atención en nada, en las relaciones con los demás, en lo que se está haciendo, en las charlas, en las clases, en lo que se come, en el espacio de recreación en donde se va, porque la mitad se está en el celular y la otra mitad si es queda con la o las otras personas prendidas con el celular.

Por lo tanto se impone la necesidad de recurrir a la esencia del hombre para recuperar algunos sustentos científicos que hacen referencia a la naturaleza comunicativa del ser humano cono tal:

El otro enfoque antropológico, consideran a la comunicación como un medio de participación conjunta de dos o más hombres en contenidos desarrolladores de la 
personalidad de cada uno de los intervinientes de la acción común, o como apertura hacia los demás y capacidad de referencia". También se puede considerar a la comunicación como un proceso terapéutico, que alivia y conforta al paciente mediante el establecimiento de un encuentro entre médico y paciente. Estralgo (1961c.p. Fermoso 1990 p. 265)

Es decir esa comunicación entre seres humanos es muy necesario para su desarrollo, por lo que cobran sentido e importancia cuando se entran en debate del momento oportuno de introducción de la informática en la formación del niño o el horario y demás condiciones a ser considerados para evitar la anulación de otras capacidades que deben ser desarrollados en la primera infancia, como la motricidad gruesa por medio de los juegos, las funciones cerebrales básicas y la motricidad fina. En este contexto corresponde analizar un punto de vista desde la teoría de la educación: "Tiene un significado pedagógico, porque solo mediante la interrelación creada entre el educador y el educando puede operarse el acto perfectivo de éstos, es decir se lleva a cabo mediante la comunicación el proceso de perfeccionamiento o formación del individuo en desarrollo y es cuando se da la comunicación educativa. Redondo (1959 c.p.Fermoso 1990, p. 265)

Es decir, el acto de la interrelación de educador y educando se desarrolla con la comunicación, la puesta en común del tema, la aclaración de dudas y necesidades de ambas partes va configurando la formación, el aprendizaje del alumno y el diagnóstico constante del avance por parte del profesor. Esta importancia se ha de subrayar ya que mediante la contextualización de la ciencia enseñada por el docente en la realidad del alumno el Docente no pierde su vital protagonismo en la educación del siglo actual, porque si seguía en su función de simple transmisor de conocimientos ya hubiera sido reemplazado por internet.

Sumando a esta exposición pedagógica se le puede sumar el argumento emocional que le hace y hará insustituible al profesor en la medida en que se va apropiando de esta realidad de la necesidad del desarrollo de tal competencia para disfrutar en primer lugar el mismo profesor en común interacción con sus alumnos.

La pregunta del buen profesor, de un formador del tercer milenio no es ¿Qué enseño?, sino ¿qué aprendo?, y mejor aún, ¿a cuántas personas he hecho felices? Deja los 
avances tecnológicos que enseñen y a los alumnos que aprendan. Tú ocúpate de hacerlos pensar y sentir 'sentipensar' De la Torre (2000, p. 89)

Ahí se enmarca la gran diferencia de funciones e importancia, la tecnología enseña y los docentes logran el aprendizaje y la felicidad de sus alumnos por medio de experiencias que fusionan sentimientos y pensamientos.

Con esto llegamos a la conclusión de que la tecnología tiene sus grandes ventajas, la solución no es enmarcar su mala utilización, es más bien orientar el aprendizaje de su buena utilización, por lo que podemos congeniar las ideas que ilustran textualmente:

Tenemos que empezar a ver claro que nos enfrentamos con un nuevo modelo de desarrollo en el que lo principal son las inversiones de nuevas mentalidades en capital humano, junto con un medio ambiente, no solo natural, sino también tecnológico, social, anímico e informacional que expresamente permita el desarrollo personal de cada individuo en particular y de las cosas en general (Elzaburu 1983, c.p. Quintana de Horák ,2006 p. 25)

El desafío por lo tanto es formar al hombre en la era de la tecnología, es hacer más hombre en la medida en que las máquinas van haciendo sus funciones anteriores, es recurrir a lo que le hace humano y no puede ser reemplazado ni imitado, su dimensión emocional.

Si educar es 'hacer al hombre' resulta obvio el esfuerzo que tenemos que asignar para 'hacerlo' cada vez mejor, para que sea cada vez más hombre. Oponer humanismo y tecnología carece de sentido, cuando la tecnología - como en el caso de la educación se pone precisamente al servicio del proceso mismo de humanización Sarramona 1986, c.p. Quintana de Horák, 2006)

Es la respuesta que aporta la ciencia, la investigación, el conocimiento a esta oposición actual de la tecnología con el ser humano, es lógico, el ser pensante, racional, creativo es el que domina todo lo creado artificialmente, solo falta formación, conocimiento, habilidad, destreza, aptitud, fusionada o reforzada con la actitud, dimensión afectiva, volitiva o emocional del ser humano, si evidenciamos la incoherencia es porque no se desarrolla la formación del "Ser humano integral", se prioriza una capacidad, inteligencia o competencia sobre otra genérica y responsable de la utilización correcta y progresiva, pudiendo aportar incluso en el perfeccionamiento evolutivo de cualquier tecnología, esa dimensión emocional o afectiva que le hace aún más único e irrepetible. 


\section{El Gobierno de las Emociones.}

Dentro de las inteligencias múltiples, focalizamos la inteligencia social o emocional, como la condición básica del éxito de las personas al saber manejar las propias emociones y la de los demás, con la gran noticia de que se puede hablar de una "Educación Emocional" al poder influenciarla y desarrollarla, aquí contextualizamos en el ámbito universitario, en donde desde sus inicios se ha trabajado la ciencia, la lógica, la razón, queriendo aprovechar tal función para actualizar tal cometido en el manejo individual y social de las emociones, es decir la función de la universidad en el "Gobierno de las emociones"

En su libro "El gobierno de la emociones" desarrolla la hipótesis de que no hay razón práctica sin sentimientos. Nadie que no sea ajeno a la psicología o a las neurociencias discute ya esta tesis:

Todas las ciencias sociales parten hoy del supuesto, exagerándolo a veces, de que somos seres emotivos y no solo racionales. De la mano de tal supuesto, lo que me propongo hacer aquí es analizar cuál es el lugar de las emociones en la ética. Las emociones son los móviles de la acción, pero también pueden paralizarla. Hay emociones que nos incitan a actuar, otras nos llevan a escondernos o a huir de la realidad. Todas las emociones pueden ser útiles y contribuir al bienestar de la persona que las experimenta, para lo cual hay que conocerlas y aprender a gobernarlas. Es posible hacerlo porque las emociones al igual que otras tantas expresiones humanas, se construyen socialmente. Es el contexto social el que enseña a tener vergüenza o a no tenerla, el que sienta la base de la confianza, el que indica que hay que temer o en qué hay que confiar, el que propicia o distrae de la compasión. Cambiamos de mentalidad o de opinión si cambiamos de sentimientos. Camps (2011.p 13)

Esta es la síntesis de la necesidad de conocer y gobernar las emociones como una manifestación humana más, al ser en forma natural positiva o negativa en función a su influencia en el bienestar o malestar de las personas, y una vez configurada dentro de la ética pueda formar parte del carácter de la persona que ha adquirido el gobierno de sus reacciones por medio de la educación emocional.

Si la función científica de la universidad es precisamente actualizar la educación como el ámbito transversal de todas las manifestaciones sociales y profesionales, en el gobierno o manejo oportuno de las emociones encuentra un paradigma muy necesario 
para responder a los desafíos actuales en que la deshumanización es inminente y solamente recurriendo a la misma naturaleza del ser humano podríamos hacer frente a este fenómeno social acuciante que empieza alienando la misma dimensión espiritual que termina afectando el cuerpo y la mente, es decir la integralidad humana. De ahí que como plantea la misma autora.

La educación moral -la padeia- iba destinada a hacer de cada uno un ser justo, prudente, magnánimo, temperante, valiente, es decir una persona habituada a reaccionar ante las distintas situaciones en que podía encontrarse poniendo de manifiesto su capacidad para la justicia, la prudencia, la generosidad o la valentía, sintiendo todos esos valores como algo propio, incorporado a su manera de ser. Y la misma sigue actualizando sus alcances sosteniendo que el discurso actual sobre las emociones pretende corregir esa tendencia y distanciarse del racionalismo hegemónico. La moralidad no se reduce solo a una especie de clasificación de las acciones como buenas o malas, correctas o incorrectas, de acuerdo con unas normas aprendidas, sino que es también una sensibilidad de acuerdo con lo cual uno siente atracción hacia lo que está bien y repulsión hacia lo que está mal. No es solo un conocimiento de lo que se debe hacer, de lo que está permitido o prohibido, sino también de lo que es bueno sentir. También la ética es una inteligencia emocional. Llevar una vida correcta, conducirse bien en la vida, saber discernir, significan no solo tener un intelecto bien amueblado, sino sentir las emociones adecuadas en cada caso. Entre otras cosas, porque si el sentimiento falta, la norma o el deber se muestran como algo externo a la persona, vinculado a una obligación, pero no como algo interiorizado o íntimamente aceptado como bueno o justo. Por ejemplo pagar impuesto no para evitar sanción, sino como imperativo moral de que es bueno redistribuir la riqueza. Camps (2011.p 15)

\section{El valor transversal de educación emocional y la razón.}

No se puede hablar de una supremacía entre la emoción y la razón, la intención del análisis es subrayar el valor de la integración de la emoción en la educación sin dejar de lado el valor reconocido de la razón como fundamento de la superioridad del hombre entre los seres vivos, de ahí que corresponde diferenciar ambos conceptos para poder comprender la necesidad de la integración oportuna y sistemática a partir de estos fundamentos. Empezamos diciendo que la razón fue reconocida siempre en el sistema nervioso, las emociones empiezan a ser reconocidas en los últimos tiempos. Recurrimos 
a la misma actora para avanzar en el valor transversal de las emociones y la razón en la manifestación humana:

Camps (2011). Cualquiera de los ámbitos de la actuación humana, sea el trabajo, la política, el ocio o la educación, tiende a ser abordado desde esa perspectiva exclusivamente emocional...De esa forma el empresario se preocupa por el clima emotivo que modela las actitudes de los trabajadores; el político se descanta con la facilidad hacia el populismo y la demagogia; los padres dan rienda suelta a los deseos de sus hijos y en la escuela desaparecen las reglas porque la represión es traumática; la publicidad comercial vende "experiencias", "sensaciones fuertes" $\mathrm{o}$, directamente emociones. En suma hay que sentir en lugar de aprender a pensar. Las emociones se convierten en una especie de culto. (p.19)

La situación expuesta nos muestra el culto a las emociones, cuando no se considera la razón, es decir todo se mueve en función a las emociones no comprendida ni asumida en su real esencia, de ahí que se generan las crisis desde las familias con repercusión social directa en todos los ámbitos, considerada así se expone una perspectiva muy negativa de las emociones en su aplicación o vivencia, que ya hemos contextualizado dentro de su carácter ético y moral, para diferenciar lo que está bien de lo que está mal. En fin se usa tal situación para relacionar con la necesidad de "pensar, razonar" en forma integral con el "sentir"

Camps (2011). El ser humano está dotado también de razón y no solo de emociones, debe desarrollar lo que los griegos llamaron la actividad contemplativa, el pensamiento, aprender a admirar lo admirable y a rechazar lo que no lo es, para lo cual debe tener razones que le indiquen qué es digno de admiración y qué no es admirable bajo ningún aspecto. Debe adquirir la capacidad de discernimiento y de saber distinguir lo que vale de lo que no vale. Capacidad que resulta de un largo aprendizaje. (p.20)

Es muy necesaria la conjunción de "pensamientos" y "sentimientos", la acción de pensar y sentir se fusionan en la necesidad de manejar las emociones, precisamente esta integración da paso a la educabilidad o posibilidad de ser educada las emociones, como cualquier área del saber humano, con el fuerte énfasis en la aplicación en la vivencia, la práctica en la interacción áulica y por sobre todo con la apertura total a las naturalezas individuales impredecibles de cada actor educativo, educador o educando inicialmente, como expresa nuestra actora de referencia al gobierno de las emociones. 
Camps (2011). Resaltar el papel de las emociones en la ética es un modo, quizá el único, de abordar el poco tratado problema de la motivación moral, un problema que la filosofía racionalista más bien elude porque nunca ha sabido respuesta a una pregunta secular: ¿por qué el conocimiento del bien y del mal no nos hacen buenas personas? Y es que son las emociones o los sentimientos las que proporcionan la base necesaria al conocimiento del bien y del mal para que el ser humano se movilice y actúe en consecuencia con ello. (p.17)

Y dando la base hasta aquí, desde las inteligencias múltiples, de la que se desprende la inteligencia social, la educación emocional, en el contexto áulico como intervienen las actitudes y las emociones en la relación y la comunicación entre educador y educando, se da la posibilidad de educar las emociones y por ende gobernarlas. Sustento que abre paso bien direccionado hacia el último apartado concluyente e integrador la "Pedagogía emocional"

\section{La Pedagogía Emocional}

\section{El aprendizaje y la Pedagogía emocional}

El desafío del docente del siglo XXI, comprueba su competencia profesional de educador cuando sus alumnos aprenden, cobra vigencia en importancia el aprendizaje como evidencia o efecto lógico de la enseñanza, es decir si hablamos de aprendizaje se presupone la enseñanza, por lo tanto lo incluye. En este supuesto se basa la importancia del Educador, como ser formado para enfrentar los desafíos de la automatización del comportamiento humano, es hora de aflorar lo genuinamente humano, sus emociones, sus sentimientos que le hacen sentir bien o mal, alegre o triste ante las situaciones vividas continuamente con los demás partiendo de esa relación intra personal que administra su realidad integral, fusionada con la razón que le permite encontrar las formas de manejar y mejorar las situaciones que la requieran, ya que aunque este bien en un momento dado la condición perfectible del hombre, lo lleva a la búsqueda de algo más, el eslabón siguiente que aunque no exista lo va creando, haciendo uso de su libertad y su creatividad. Contextualizar en el ámbito universitario conlleva la preparación para el ejercicio profesional posterior, pudiendo hacer alusión a la funcionalidad de lo aprendido en el desempeño de la persona que recibe la formación, recurrimos a lo expuesto por el siguiente actor: 
...en educación, el concepto de aprendizaje se refiere mucho más a la adquisición de conocimientos enmarcados en las aulas, a la adquisición de habilidades prácticas o técnicas, sobre todo aquellas con respecto a la vida profesional, o también a la adquisición de hábitos de vida como la disciplina, la responsabilidad o la motivación. Por otra parte en el ámbito educativo también se define el aprendizaje como "la adquisición y la integración de nuevos conocimientos, con el fin de poderlos reutilizar funcionalmente. Tardif (c.p.Chabot2009, p.2)

El cómo lograr la funcionalidad de lo aprendido o mejor aún comprobar el aprendizaje al sentirse realizado con cada aplicación de conocimientos, habilidades, destrezas, actitudes y aptitudes es decir la integración de capacidades en la competencia de la profesión para la que ha sido formado, requiere de toda una gestión pedagógica administrativa, desde el diseño y desarrollo curricular, así como en la formación de los profesores universitarios para ejercer la práctica áulica, lo que supone un tacto pedagógico didáctico para llegar a los educandos en esa etapa evolutiva más exigente por la madurez que busca el sentido y la lógica de las diversas áreas del saber.

De ahí que se requiere puntualizar la pedagogía, el cómo orientar el aprendizaje, por lo que adoptamos lo expresado por los hermanos Chabot 2009 señala que, dentro del contexto educativo, ese aprendizaje se inscribe, en gran parte, en una gestión pedagógica, de tal forma que un buen aprendizaje se asocia estrechamente a una buena Pedagogía. Y si bien lo cognitivo y lo técnico, busca la integración de las capacidades mencionadas...el cuestionamiento se asume desde otra perspectiva. No porque lo cognitivo no sea importante, sino porque así el panorama estaría incompleto y no sería capaz de responder todas las preguntas relativas al aprendizaje y sus dificultades asociadas. En el libro Pedagogía Emocional del mencionado actor, se enfatiza sobre otro campo de competencias: las emocionales, y sobre las partes de le cerebro que intervienen en ellas.

Muchos indicios, tanto científicos como inductivos, llevan a creer que las competencias emocionales explican en gran parte las dificultades de aprendizaje, como también lo señalan los éxitos logrados en el área. En la monografía de la Organización para la Cooperación y el Desarrollo Económico (OCDE) se puede leer lo que sigue:

Lo emocional es en parte responsable del dominio cognitivo global presente en los niños y adultos, y debemos tenerlo en cuenta como se merece.... La neurociencias 
cognitivas contemporáneas proporcionan las herramientas para realizar análisis por componentes sutiles, de tal manera que se traten algunas tareas específicas. Tradicionalmente dichos estudios se han concentrado sobre los aspectos cognitivos del aprendizaje. Hemos sido negligentes al no efectuar esos análisis sobre las zonas asociadas a lo emocional y a lo afectivo, pues el papel que los mencionados aspectos desempeñan dentro de las funciones cognitivas no se reconocía. En consecuencia, la información sobre ese campo es dispersa e incompleta. La ausencia de pautas de medición y de fundamentos teóricos limita los progresos en los estudios de la regulación emocional dentro de la práctica educativa. OECD

Son más antecedentes, utilizados como argumentos que respaldan la consistencia de una nueva visión de la Pedagogía: La Pedagogía emocional, aquella que afirma que para aprender es necesario sentir. Por lo tanto para hacer válida y completa esta expresión "para aprender es necesario sentir, se necesita ampliar la epistemología que lo sustenta, enfatizando lo que Chabot (2009, p. 7) menciona como que tradicionalmente, se reconocen dos grandes campos de competencias: las cognitivas y las técnicas. Las competencias cognitivas están asociadas al saber y al conocimiento...las competencias técnicas, están asociadas al saber hacer y todo lo atinente a las habilidades técnicas. Se agregan las competencias racionales, aquellas que permiten interactuar con los otros y las competencias emocionales, aquellas que permiten sentir las cosas, experimentar emociones y reaccionar en consecuencia.

Todos hemos vivido experiencias que demuestran que las emociones interfieren con las otras competencias. Algunas veces las emociones ensombrecen las capacidades intelectuales, procedimentales o relacionales; otras las realzan, las estimulan y las facilitan. Aquí logramos la relación entre el aprendizaje que ya no es mero conocimiento de sustentos teóricos e incluso su aplicación técnica, sino más bien se busca que las personas logren su felicidad por medio de la educación como un todo sumado o integrado de aprendizajes, es decir el profesional debe sentirse integralmente realizado, incluido fuertemente su "bien estar" - "Estar - bien", esa plenitud profesional también debe ser a la vez una plenitud personal, de esa forma se dará respuesta al perfil de egreso de cualquier institución educativa, mencionada incluso en la Constitución Nacional, la educación busca el desarrollo integral de la persona humana" y que ironía tanto tiempo ha descuidado la dimensión afectiva emocional. 
Y bien por lo tanto ahora surge la necesidad de responder al cómo implementar la Pedagogía Emocional en la formación profesional universitaria, y bien sabemos que en ciencias de la educación, el "cómo" hace referencia a métodos, técnicas, estrategias, procedimientos.

Lo emocional en las estrategias pedagógicas. Recurrir a lo emocional en las estrategias pedagógicas.

Hablamos de "aprendizaje de las emociones", vamos a necesitar recurrir a estrategias, el cómo desarrollar la inteligencia para lograr el aprendizaje emocional.

Precisamente, en las implementación de estrategias pedagógicas, cualquiera sea la técnica, será necesario comprender la importancia de las competencias emocionales y de las emociones en los procesos de aprendizaje, porque ahí es donde se encuentra el corazón de la Pedagogía emocional. Para sopesar el enfoque cognitivo en educación, que atribuye a capacidades intelectuales y estrategias cognitivas las dificultades de aprendizaje.

Para reforzar aún más la necesidad de lo emocional en las estrategias como parte de esa pedagogía que busca el desarrollo integral de las personas podemos recurrir a varios actores que sustentan investigaciones un poco inquietantes en el campo de la educación que mostraron, por ejemplo, que no hay correlación entre el éxito escolar y el éxito profesional. Se puede decir entonces que los eventos que tienen una carga emocional se inscriben con más fuerza en la memoria declarativa. Sin embargo, las emociones no refuerzan la memoria en todas las circunstancias. En el caso del estrés por ejemplo, la reacción emocional que lo acompaña puede perjudicar el resultado memorístico. Así pues, las emociones pueden tener un impacto tanto de refuerzo como de atenuación sobre la memoria y sobre el aprendizaje. Las emociones negativas tienen el poder de influir considerablemente sobre el conjunto de las funciones cognitivas e intelectuales.

Cuando aludimos al aprendizaje, a las estrategias, es porque la inteligencia emocional puede ser influida, ha sido demostrada científicamente como tal desde las bases biológicas de la conducta humana, focalizando incluso los órganos encargados de las funciones emocionales. Las conexiones nerviosas gobernadas por la amígdala tienen ramificaciones que dan esa última alerta cuando una emoción intensa hace aparición. La atención, la percepción, la memoria de trabajo, el juicio y el razonamiento se afectan con las emociones negativas; son muchos los aportes científicos que apuntan a esa tesis 
y se puede afirmar con certeza, entonces, que las emociones negativas son responsables de un número importante de dificultades de aprendizaje. (Chabot 2009, p, 56, 74)

El mismo autor hace referencia a afirmaciones de otros estudiosos que fueron acuñando las concepciones referentes al tema: la inteligencia emocional, cuyo concepto se lanzaría por primera vez en 1990. Peter Salovey y John Mayer en 1990/97 describen entonces la inteligencia emocional como: la habilidad para percibir los propios sentimientos y emociones y los de los otros, para diferenciar entre ellos y para utilizar esas informaciones como guía de las acciones y de los pensamientos.

En 1995 se dio a conocer en público un concepto de inteligencia emocional, gracias a Daniel Goleman definió la inteligencia emocional como: la capacidad de reconocer los propios sentimientos y los de los otros, de motivarnos nosotros mismos y de administrar bien las emociones en sí mismos y en las relaciones con el prójimo.

En orden de ideas la inteligencia emocional se definió como "la habilidad de sentir y/o administrar sentimientos cuando ellos facilitan los pensamientos; la habilidad de comprender las emociones y los conocimientos emocionales; y la habilidad de administrar las emociones para favorecer el crecimiento emocional e intelectual". (Chabot, 2009, p, 80)

Con esto como base e impulso, se puede asociar el éxito o el fracaso escolar o del aprendizaje con la inteligencia emocional, ya que una vez determinada como habilidad de sentir y administrar las emociones, en otras palabras, se pueden incidir, influir, condicionar o estimular esa manifestación emocional, por medio de una pedagogía emocional que utilice las estrategias oportunas e incluso en forma sistemática que empiece desde la formación del hogar. Ahora bien podemos enfatizar como administrar emociones desfavorables en el aprendizaje por medio de las estrategias que correspondan en forma intencionada.

\section{Administrar emociones desfavorables en el aprendizaje.}

La clave de la pedagogía emocional, una vez considerada su esencia y su posibilidad de ser influenciada, estaría por lo tanto en la administración de las manifestaciones desfavorables del aprendizaje, la función de la Universidad debe centrarse en cómo evitar, detectar y atender los indicios de esas manifestaciones". (Chabot, 2009, 109) afirma que la primera condición para el buen aprendizaje consiste en sentirse bien. En cualquier terreno, pues, las emociones negativas afectan todos los procesos mentales, 
desde la atención más elemental hasta los procesos intelectuales y cognitivos más complejos. El aprendizaje está, pues, en función del estado emocional de quien aprende y en ello el educador cumple un papel importante, si quiere favorecer el proceso de sus alumnos. Por lo anterior, se sistematiza puntualmente del autor mencionado:

- Cualidades del profesor: debe desarrollar sobre todo dos cualidades esenciales para su desempeño: la empatía y la condescendencia.

- Etapas de la inteligencia emocional: la identificación, la expresión, la comprensión y la gestión de emociones. Se ve que la escucha empática es una necesidad para quien quiere ayudar a otro a identificar y a expresar sus emociones.

- Componentes de la emoción: las Emociones pueden ser administradas y pueden ser examinados por medio de sus componentes. Así se pueden administrar las expresiones no verbales, las reacciones fisiológicas y las reacciones de comportamiento. Así mismo se puede administrar lo cognitivo y manejar las necesidades irracionales.

- Se pueden administrar las emociones en segundo plano, con énfasis en las diferentes fuentes de placer que un ser humano es susceptible de sentir: los fisioplaceres, los socioplaceres, los ideoplaceres. Se analiza la manera más eficaz de motivar el lóbulo prefrontal izquierdo por medio de la meditación.

En fin la cualidades del profesor como actor formado, lo aplica en la identificación y atención de cada una de las etapas sumadas a la examinación de los componentes de las emociones. Fusionando según correspondan a satisfacciones o placeres del ámbito fisiológico, sociológico o ideológico. En resumen, la teoría de los procesos antagonistas de Salomón permite comprender toda la significación de placer, por mínimo que sea, en una trayectoria de aprendizaje. Aprender necesariamente es hacer frente a dificultades, a momentos desagradables, de duda o, así mismo, de desaliento. Sería ilusorio pensar que se puede aprender sin esfuerzo y sin vivir momentos de disgusto. Pero también es irreal creer que es posible aprender sin experimentar éxito y sentir momento de bienestar.

Los éxitos y los placeres sentidos durante el aprendizaje son el antídoto contra el abandono escolar o falta de compromiso frente a los procesos de aprendizaje en sí. Todo individuo tiene necesidad de sentir satisfacción y de relacionarse con cualquier forma de placer asociado a su trayectoria de aprendizaje. Requiere sensaciones positivas cuando 
aprende. La pérdida de placer conduce inexorablemente al desaliento, al abandono o al fracaso.

\section{El verdadero aprendizaje es emocional.}

Se hace alusión a la fusión de lo cognitivo y lo emocional en la naturaleza racional del ser humano, se entiende que el verdadero aprendizaje no es la repetición mecánica de conocimientos, habilidades, destrezas en procedimientos técnicos, sino es llagar a la actitud, al encuentro de lógica y sentido incluso en forma inherente a la individualidad de cada persona de acuerdo a su forma de ser, sus gustos, su vocación. Por eso según el mismo autor de referencia Chabot dice que hay que animarse a preguntar a las personas cómo les gusta aprender. Inquirir sobre lo que precisan sentir cuando asimilan algo nuevo. Ahora bien cada persona funciona de distinta manera. Otros tienen necesidad de comprender porque hacen lo que se les pide. Otros más quieren tener pequeños éxitos a lo largo de su recorrido. También hay otros que se sienten bien sólo cuando tienen la sensación de captar todo en conjunto. Las distintas observaciones permiten comprender que algunas personas se inclinan por lo nuevo y diferente, y otras, a la inversa, por lo familiar y rutinario. La experiencia de educador permite constatar que algunos individuos no reaccionan cuando vislumbran la amenaza de un virtual fracaso, mientras otros reaccionan muy fuertemente. Así mismo, algunos buscan aprobación y apoyo mientras que otros parecen ser totalmente indiferentes.(Chabot, 2009, p. 115)

Se insiste en el hecho de que el verdadero aprendizaje no es cognitivo pero sí emocional. Por ejemplo, leer un libro es, en gran medida, un ejercicio cognitivo. Se espera que esta lectura sepa despertar en los profesores el deseo de "hacer sentir", en primer lugar a aquellos a quienes enseña. Se espera no sólo que se hayan comprendido los conceptos, también que se hayan sentido y que, al mismo tiempo que se leyó, se haya podido reflexionar sobre la realidad cotidiana del educador y formador.

"El ser humano es sensible y por ello necesita sentir para aprender"

\section{Material y Métodos}

Para el sustento bibliográfico de la variable "Pedagogía emocional" se basa en el material básico, Pedagogía emocional. Sentir para aprender. Integración de la inteligencia emocional en el aprendizaje. De Daniel Chabot y Michel Chabot. En lo que concierne a la formación profesional, al aprendizaje y su efecto en el desempeño se recurre al material El Gobierno de las Emociones de Victoria Camps y La Inteligencia 
Emocional de Daniel Goleman. En lo que concierne a la Educación Superior se respalda en la Constitución Nacional 1992, Ley Nº 4995 de la Educación Superior, el Libro Blanco del CONES.

El método básico inductivo, deductivo a partir de la investigación bibliográfica, con refuerzo de un trabajo de campo orientado por una investigación con enfoque mixto cualitativo y cuantitativo por la utilización de los instrumentos en el procesamiento de datos levantados de la Facultad de Ciencias Aplicadas específicamente de la Carrera de Ingeniería Ambiental, de las fuentes primarias, alumnos, docentes y autoridades.

\section{Resultados, Discusión}

Análisis comparativo de la percepción de las fuentes primarias Alumnos y Docentes en función a las variables fundamentales.

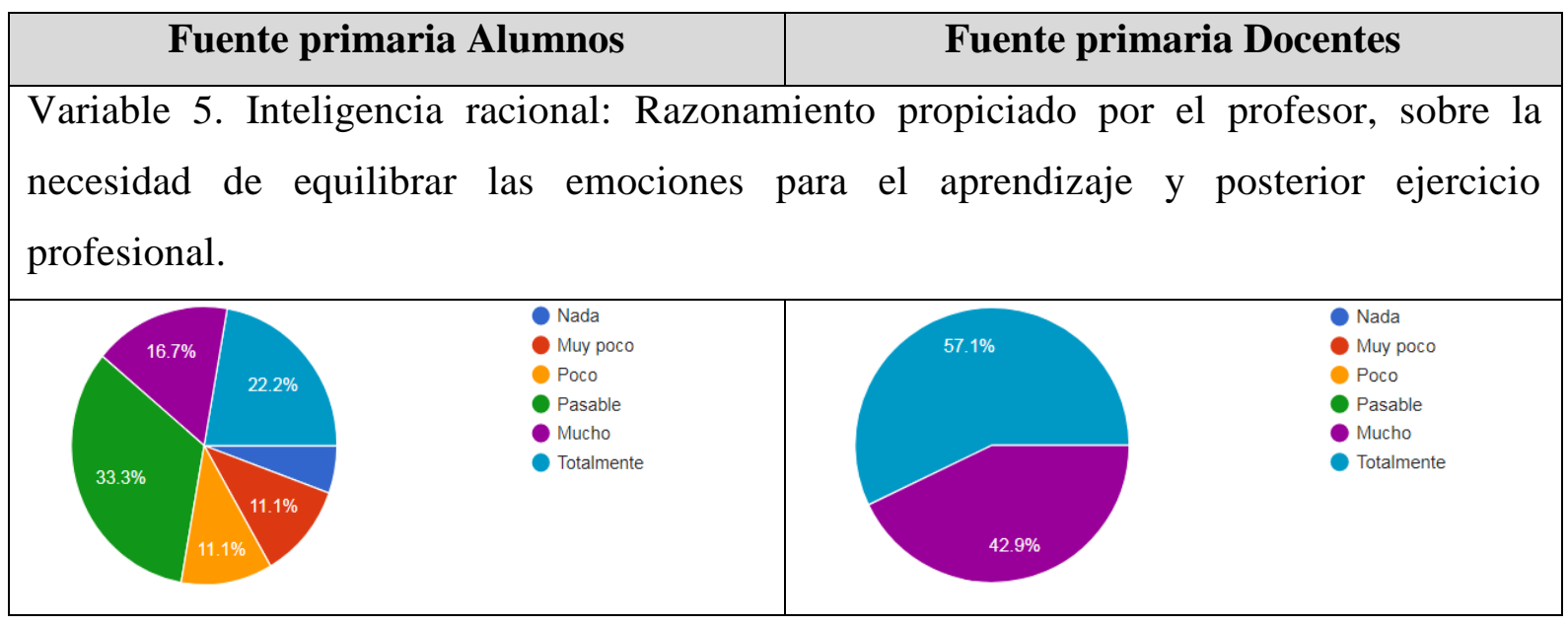

Variable 6. Inteligencia emocional: Percepción de que las emociones como la alegría, entusiasmo, buen trato, ayudan a aprender en clase, desarrollar proyectos de investigación y extensión.

Variable 7. Situaciones de aprendizaje: Desarrollo de técnicas por el profesor que han
propiciado el aprendizaje significativo de los alumnos.




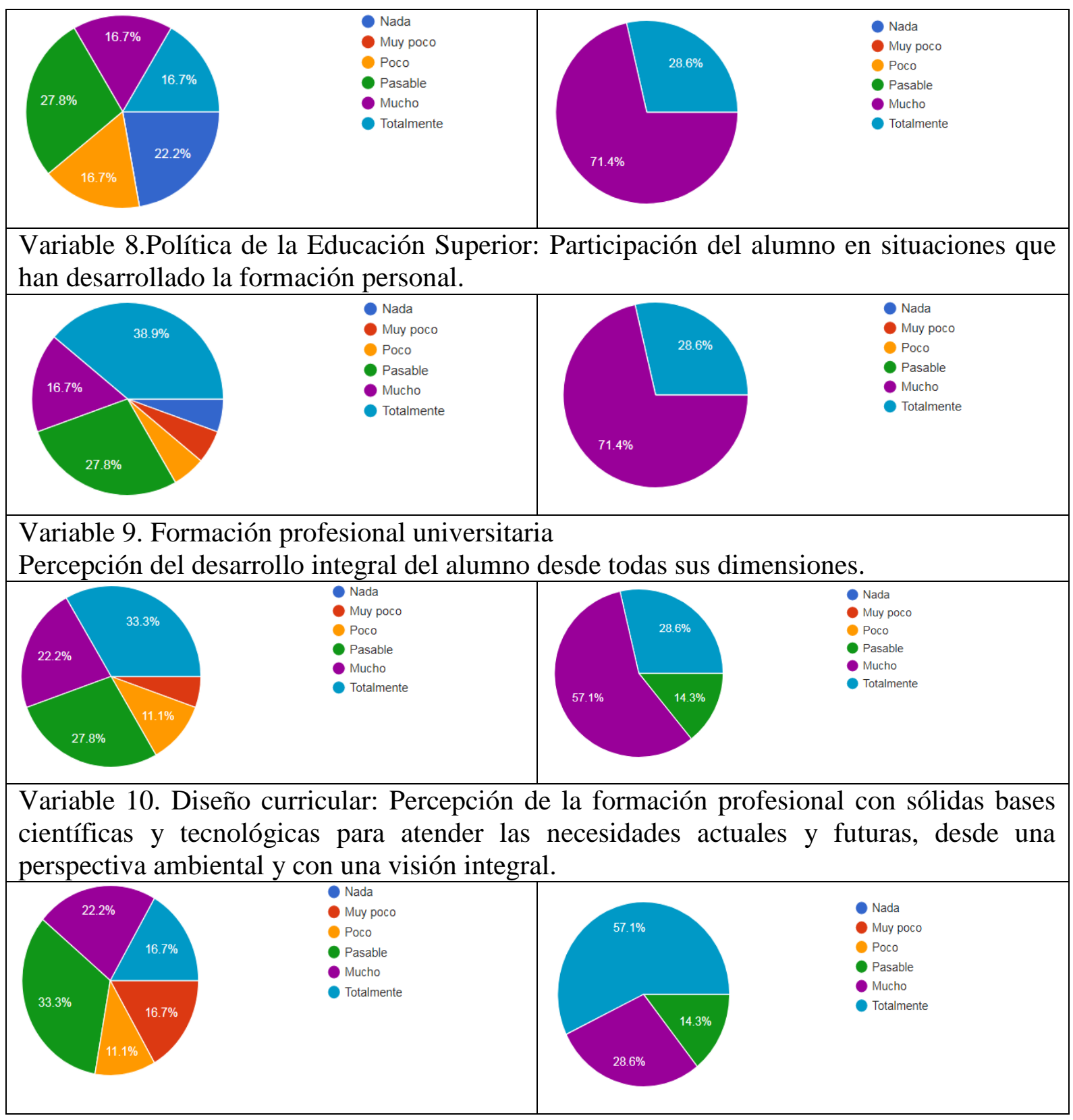

Fuente: Elaboración propia. Gráficos generados por google forms.

En forma general las variables son percibidas entre pasable, mucho y totalmente, lo que arroja indicios de la consideración de la pedagogía emocional, desde las variables inteligencia emocional y la inteligencia racional desde las situaciones de aprendizajes, la política de la educación superior, la formación profesional universitaria y el diseño curricular.

\section{Se destaca la consideración de pasable por los alumnos en tres variables:}


En la variable 5, inteligencia racional, en la alternativa: El razonamiento propiciado por el profesor, sobre la necesidad de equilibrar las emociones para el aprendizaje y posterior ejercicio profesional. Mientras el docente lo considera como totalmente.

Variable 7, situaciones de aprendizaje, en la alternativa: Desarrollo de técnicas por el profesor que han propiciado el aprendizaje significativo de los alumnos. Mientras el docente lo considera como mucho.

Variable 10. Diseño curricular, en la alternativa: percepción de la formación profesional con sólidas bases científicas y tecnológicas para atender las necesidades actuales y futuras, desde una perspectiva ambiental y con una visión integral. Mientras el docente lo considera como totalmente.

Por lo tanto los alumnos preciben como pasable la consideración de la inteligencia racional para lograr equilibrar las emociones para el aprendizaje y posterior ejercicio profesional, al igual que aspectos relacionados a la pedagogia emocional como situaciones de aprendizajes significativas y el diseño curricular con visión integral.

\section{CONCLUSIÓN}

Para responder a la interrogante ¿Es posible incrementar en la formación profesional universitaria la Pedagogía emocional?, ¿Se podría lograr mejores resultados de aprendizajes? y por consiguiente ¿podría egresar un estudiante con un perfil que incorpore la competencia emocional en su formación profesional, afirmando una vuelta significativa con la expresión la Universidad, sí acorta las orejas?

Se concluye que la pedagogía emocional está implicada en la formación profesional universitaria, en el desarrollo de contenidos actitudinales, consideración de la formación integral, ética, valores, transformación de pensamiento, asignaturas humanas y ambientales como función sustantiva de la docencia, en extensión e investigación, desde las gestiones ambientales que involucran las emociones. Se enfatiza una consideración indirecta y autónoma de aplicación que requiere ser atendida en forma sistemática y funcional.

En la actualidad casi en forma empírica se va detectando prácticas condicionadas por la necesidad de entablar una relación pedagógica afable y confiable, exteriorizando sentimientos por medio de situaciones de aprendizajes relacionados con la vida real y la problemática publicada en los medios de comunicación con respecto a la futura incorporación profesional de los estudiantes. 
Es así que se demuestra la implicancia de la Pedagogía emocional en la formación profesional universitaria. Las estrategias utilizadas son desde las más prácticas, análisis de los propios sentimientos, emociones, en función a las propias anécdotas, entrevistas con profesionales exitosos de la misma carrera, recortes de la realidad emergente encontrada en las noticias, documentales, videos, ejemplos de la vida real, fusionando siempre la teoría con la práctica, de tal forma que el estudiante le encuentre el sentido lógico y lo convenza, dejando en su subconsciencia el ideal a ser logrado con el gobierno de las emociones, como objetivo de la pedagogía emocional.

Respaldan esta implicancia emocional universitaria los sustentos científicos, que van desde la consideración de reportes escritos de la realidad social actual cegada por la tecnología que propicia la globalización y la comunicación en la única aldea planetaria, la imponente y lógica consideración de las inteligencias múltiples y dentro de la misma la intrapersonal e interpersonal como transversal de todas las demás facultades humanas manifiestas, derivando en la inteligencia emocional de Goleman, apoyada en su aplicación con sustentos filosóficos de todas la épocas con la necesidad de tener como una brújula a las emociones, que gobierne la vida individual y social de las personas. La inteligencia emocional, timón de nuestras vidas, al ser comprobada la posibilidad de ser aprendida, esta abarcada en la Pedagogía Emocional, que a más de lograr el sentir para aprender ha de constituirse en una competencia prospectiva y proactiva aplicable en la práctica del ejercicio profesional con los desafíos propios de la insipiencia profesional y la carrera que condiciona la fusión de la razón con la emociones.

\section{REFERENCIAS BIBLIOGRAFICAS}

Aebli, Hans, 12 formas básicas de enseñar (1998). Narcea, Madrid

Ander - Egg, E. (2010) Cinco claves para mejorar la educación paraguaya. Asunción. Servilibro.

Antunes, C. (2002) Las Inteligencias Múltiples. Cómo estimularlas y desarrollarlas. México Alfaomega

Avolio D.S. (1996) Los Proyectos para el trabajo en el aula. Pautas para u diseño. Buenos Aires.Marymar

Camps, V (2011) El gobierno de las emociones. Barcelona.Herder Editorial.

Cardozo R.I. (2003) La práctica de la escuela activa. Fundación en Alianza. Asunción Paraguay. 
Chabot, D y M. (2009). Pedagogía Emocional. México Alfaomega.

Convención Nacional Constituyente. Sancionada el 20 de junio de 1992.Constitución Nacional de la República del Paraguay. abc COLOR.

Díaz H. C. (2004). Educar en valores. Editorial Trillas. México.

Fermoso Paciano (1990). Teoría de la Educación. México. Trillas.

Fernández B. B. (2010) “A sacudirse” Claves para la construcción de la nueva República. Editora libre. Asunción Paraguay.

García, J. (2017). Libro Blanco para la Educación Superior. Nanearanduka tuichavéva. Primera Edición-Asunción: Consejo Nacional de Educación Superior.

Goleman, D. (2000) La inteligencia emocional. Por qué es más importante que el cociente intelectual. Argentina Ediciones

MEC. (2002). El currículum de la Educación Media y los transversales.

MEC-CONEC-UNA (2006). Paraguay: Universidad 2020 .Ediciones y Arte. S. R. L.

Morin E. (2002) Los siete saberes necesarios para la educación del futuro. Ediciones nueva visión. Argentina.

Núñez, L, (2008) Pedagogía emocional: una experiencia de formación en competencias emocionales en el contexto universitario. España Universidad de Sevilla.

Quintana de H. C. (2006) CONEC. Estudio de la Formación y Capacitación Docente. Primera Edición. Etigraf.

Rivarola D. (2004). La Educación Superior Universitaria en el Paraguay. Ediciones y Arte. S.R. L.

Jacks Delors y otros (1996). La Educación encierra un tesoro. Santillana. Ediciones UNESCO. Madrid. 